\title{
Penggunaan Structural Equation Modeling (SEM) untuk Menganalisis Faktor yang Mempengaruhi Loyalitas Nasabah (Studi Kasus : PT Bank Negara Indonesia (BNI) KCU Ambon)
}

\author{
Ralf Latumeten $^{1}$, Yopi Andry Lesnussa ${ }^{1 *}$, Francis Y. Rumlawang ${ }^{1}$ \\ e-mail:yopi_a_lesnussa@yahoo.com \\ ${ }^{1}$ Jurusan Matematika, Fakultas Matematika dan Ilmu Pengetahuan Alam \\ Universitas Pattimura, \\ Jln. Ir. M. Putuhena, Kampus Unpatti, Poka-Ambon, Indonesia 97233
}

\begin{abstract}
Structural Equation Modeling (SEM) is a statistical modeling technique that is very cross-sectinal, linear, and complex. SEM is a combination of two multivariate techniques i.e. confirmatory factor analysis and path analysis. In this research will be applied Structural Equation Modeling to analyze factors influencing customer loyalty. Where researchers take two factors: bank image and customer satisfaction. The data used in this study is the primary data obtained by using questionnaires to customers of PT Bank Negara Indonesia (BNI) KCU Ambon with a total sample is 102. This study aims to determine the effect of bank image and customer satisfaction on customer loyalty. The results of this study note that the model has been suitable to be used to identify and meet the criteria of goodness of fit. From the analysis of the model, the tvalue for the latent variable of the bank image is 0.42 and the $t$-value for the latent variable of customer satisfaction is 2.84. With a critical value of 1.96 (to 5\% real level) it can be concluded that the latent variable of the bank's image has an influence on customer loyalty while the latent variabel of customer satisfaction has no influence on customer loyalty.
\end{abstract}

Keywords : SEM, Loyalty, Image, Satisfaction, Bank, Customer

\begin{abstract}
ABSTRAK
Structural Equation Modeling (SEM) adalah suatu teknik pemodelen statistik yang bersifat sangat cross-sectinal, linier, dan kompleks. SEM merupakan gabungan dari dua teknik multivariat yaitu analisis faktor konfirmatori dan analisis jalur. Pada penelitian ini akan diterapkan Structural Equation Modeling untuk menganalisa faktor yang mempengaruhi loyalitas nasabah. Dimana peneliti mengambil dua faktor yaitu citra bank dan kepuasan nasabah. Data yang digunakan dalam penelitian ini adalah data primer yang diperoleh dengan menggunakan kuisioner kepada nasabah PT Bank Negara Indonesia KCU Ambon dengan jumlah sampel sebanyak 102. Penelitian ini bertujuan untuk mengetahui pengaruh citra bank dan kepuasan nasabah terhadap loyalitas nasabah. Hasil dari penelitian ini diketahui bahwa model yang disusun telah cocok digunakan untuk mengidentifikasi dan memenuhi kriteria goodness of fit. Dari hasil Analisa terhadap model tersebut diperoleh nilai t-value untuk variabel laten citra bank adalah 0,42 dan nilai t-value untuk variabel laten kepuasan nasabah adalah 2,84. Dengan nilai kritis 1,96 (untuk taraf nyata 5\%) disimpulkan bahwa variabel laten citra bank mempunyai pengaruh terhadap loyalitas nasabah sedangkan variabel laten kepuasan nasabah tidak mempunyai pengaruh terhadap loyalitas nasabah.
\end{abstract}

Kata Kunci : SEM, Loyalitas, Citra, Kepuasan, Bank, Nasabah 


\section{PENDAHULUAN}

Pelayanan adalah suatu kegiatan yang dilakukan oleh perusahaan untuk kepentingan orang lain bukan hanya untuk melayani tetapi bertujuan untuk membangun kerja sama jangka panjang dengan prinsip saling menguntungkan. Sebuah perusahan mampu memberikan pelayanan yang baik apabila perusahan tersebut memahami keinginan konsumen dan dapat memberikan nilai tambah dimata konsumen (Amanullah, 2012).

Perusahaan jasa pada saat ini lebih menekankan pada konsep pemasaran yang melakukan pendekatan kepada konsumennya, perusahaan memperhatikan bahwa kepuasan konsumen menjadi hal yang penting bagi kemajuan perusahaannya. Dasar untuk membangun loyalitas nasabah adalah memberikan kepuasan kepada konsumen lewat produk atau jasa yang ditawarkan oleh sebuah perusahan (Infobank, Januari 2008). Dalam penelitian ini, pelayanan yang dimaksudkan adalah pelayanan yang diberikan oleh pihak bank.

Industri perbankan saat ini telah menyadari bahwa nasabah yang loyal tidak hanya mempertimbangkan faktor bunga atau kecanggihan dan kelengkapan fitur dari suatu produk perbankan, tetapi lebih kepada nilai (value) yang didapatkan dari apa yang ditawarkan oleh pihak bank (Bielen et al, 2007). Kepuasan nasabah dan loyalitas nasabah diyakini mampu memberikan dampak positif untuk kelangsungan bank (BNI) baik dalam jangka pendek maupun untuk jangka Panjang (Liu \& Wu, 2007).

\section{Structural}

Equation

Modeling atau SEM merupakan salah satu teknik analisis statistik yang digunakan untuk membangun dan menguji model statistik dalam bentuk model-model sebab akibat (Prastuti,
2011). Analisis data dengan menggunakan SEM digunakan untuk memeriksa dan membenarkan suatu model (Hair et.al, 2006). Model-model yang dimaksud diantaranya adalah analisis regresi (regression analysis), analisis jalur (path analysis) dan analisis faktor konfirmatori (confirmatory factor analysis) (Hox Bechger, 1998).

\section{BAHAN DAN METODE}

Penelitian ini merupakan studi kasus dengan menerapkan Structural Equation Modeling (SEM) untuk menganalisis faktor yang mempengaruhi loyalitas nasabah pada PT Bank Negara Indonesia KCU Ambon. Data yang digunakan adalah data primer yang diperoleh dari kuisioner yang disebar dengan jumlah responden sebanyak 102 orang. Program yang dipakai dalam penelitian ini adalah LISREL 8.80.

\section{HASIL DAN PEMBAHASAN}

\section{Gambaran Umum Responden}

Berikut merupakan data gambaran responden yang digunakan dalam penelitian ini berdasarkan jenis kelamin, kategori usia dan jenis pekerjaan, sebagai berikut:

Tabel 1. Responden Berdasarkan Jenis Kelamin

\begin{tabular}{|c|c|c|}
\hline $\begin{array}{c}\text { Jenis } \\
\text { Kelamin }\end{array}$ & Jumlah & Persentase \\
\hline Laki-Laki & 43 & $42,2 \%$ \\
\hline Perempuan & 59 & $57,8 \%$ \\
\hline Total & 102 & $100 \%$ \\
\hline
\end{tabular}

Tabel 2. Responden Berdasarkan Usia \begin{tabular}{l|l|l|} 
Usia & Jumlah & Presentase \\
\hline
\end{tabular} 


\begin{tabular}{|c|c|c|}
\hline$<20$ Tahun & 18 & $17,6 \%$ \\
\hline 20-29 Tahun & 48 & $47,1 \%$ \\
\hline $30-40$ Tahun & 29 & $28,4 \%$ \\
\hline$>40$ tahun & 7 & $6,9 \%$ \\
\hline Total & 102 & $100 \%$ \\
\hline
\end{tabular}

Tabel 3. Responden Berdasarkan Pekerjaan

\begin{tabular}{|c|c|c|}
\hline Pekerjaan & Jumlah & Presentase \\
\hline Pelajar/Mahasiswa & 43 & $42,1 \%$ \\
\hline PNS & 26 & $25,5 \%$ \\
\hline Lainnya & 33 & $32,4 \%$ \\
\hline Total & 102 & $100 \%$ \\
\hline
\end{tabular}

\section{Uji Validitas dan Reliabilitas Data}

Jumlah sampel untuk diuji validitas dan reliabilitas sebanyak 30 dengan sampel yang digunakan adalah sampel yang diperoleh diluar dari sampel yang digunakan untuk penelitian. Untuk $\alpha=0,05$ dan $n=102$ maka pada tabel $r$ diperoleh nilai $r_{\text {tabel }}=0,1946$ sehingga uji validitas dan reliabilitas sebagai berikut:

Tabel 4. Hasil Uji Validitas

\begin{tabular}{|c|c|c|c|}
\hline \multirow{2}{*}{ Variabel } & \multicolumn{2}{|c|}{ Validitas } & \multirow{2}{*}{ Ket } \\
\cline { 2 - 3 } & $r_{\text {hitung }}$ & $r_{\text {tabel }}$ & \\
\hline $\mathrm{X} 1$ & 0,560 & 0,1946 & Valid \\
\hline $\mathrm{X} 2$ & 0,548 & 0,1946 & Valid \\
\hline $\mathrm{X} 3$ & 0,441 & 0,1946 & Valid \\
\hline $\mathrm{X} 4$ & 0,568 & 0,1946 & Valid \\
\hline $\mathrm{X} 5$ & 0,493 & 0,1946 & Valid \\
\hline $\mathrm{X} 6$ & 0,561 & 0,1946 & Valid \\
\hline $\mathrm{Y} 1$ & 0,604 & 0,1946 & Valid \\
\hline $\mathrm{Y} 2$ & 0,619 & 0,1946 & Valid \\
\hline $\mathrm{Y} 3$ & 0,423 & 0,1946 & Valid \\
\hline $\mathrm{Y} 4$ & 0,398 & 0,1946 & Valid \\
\hline
\end{tabular}

Untuk reliabilitas, nilai cronbach's alpha yang diperoleh adalah $0,736 \quad(>0,6)$ sehingga data tersebut reliabel.

\section{Uji Normalitas}

Dalam penelitian ini data yang diperoleh harus berdistribusi normal agar tingkat validitas hasil pengolahannya baik. Menurut Ghozali \& Fuad (2008), normalitas dibagi menjadi dua yaitu Univariate Normality (Normalitas Univariat) dan Multivariate Normality (Normalitas Multivariat).

Asumsi normalitas dapat diuji dengan nilai statistik untuk skewness dan kurtois. Apabila nilai $\mathrm{z}$ skewness dan kurtois adalah signifikan (kurang dari 0,05 pada tingkat kepercayaan $5 \%$ ) maka dapat dikatakan distribusi data tidak normal. Sebaliknya jika nilai z skewness dan kurtois tidak signifikan (lebih dari 0,05 pada tingkat kepercayaan 5\%) maka dapat dikatakan distribusi data normal (Ghozali \& Fuad, 2008).

Normalitas univariat dan normalitas multivariat data yang digunakan dalam penelitian ini dapat diuji normalitasnya, seperti yang ditunjukan pada Tabel 5, dan Tabel 6, sebagai berikut :

Tabel 5. Uji Normalitas Univariat

\begin{tabular}{|lllllll|}
\hline Variable Z-Score P-Value & Z-Score P-Value & Chi-Square P-Value \\
X1 & -0.327 & 0.744 & -1.008 & 0.313 & 1.124 & 0.570 \\
X2 & -0.400 & 0.689 & -1.010 & 0.313 & 1.180 & 0.554 \\
X3 & -0.205 & 0.838 & -0.576 & 0.564 & 0.374 & 0.829 \\
X4 & -0.271 & 0.786 & -0.728 & 0.466 & 0.604 & 0.739 \\
X5 & -0.146 & 0.884 & -0.587 & 0.557 & 0.366 & 0.833 \\
X6 & -0.128 & 0.898 & -0.762 & 0.446 & 0.596 & 0.742 \\
Y1 & -0.118 & 0.906 & -0.392 & 0.695 & 0.168 & 0.920 \\
Y2 & -0.259 & 0.796 & -0.805 & 0.421 & 0.716 & 0.699 \\
Y3 & -0.058 & 0.954 & -0.499 & 0.618 & 0.252 & 0.882 \\
Y4 & -0.265 & 0.791 & -0.503 & 0.615 & 0.323 & 0.851 \\
& & & & & & \\
\hline
\end{tabular}

Dalam pengujian normalitas di atas , data dapat dikatakan berdistribusi normal jika $P$-Value Skewness dan Kurtois $>0,05$. Berdasarkan hasil output di atas dapat dilihat bahwa keseluruhan variabel mempunyai nilai yang lebih dari 0,05 sehingga dikatakan berdistribusi normal.

Tabel 6. Uji Normalitas Multivariat 


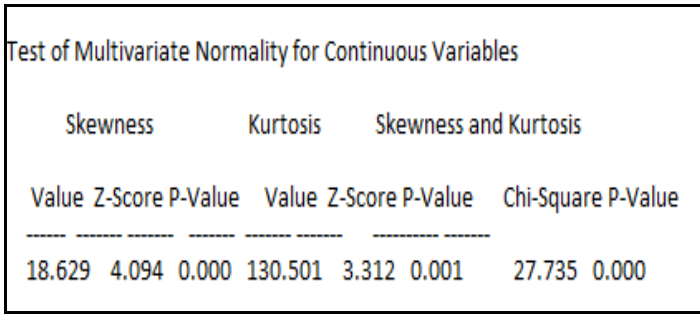

Pada pengujian normalitas multivariat nilai $P$-Value Skewness dan Kurtois adalah $0,000 \quad(<0,05)$ sehingga dikatakan tidak normal. Ada dua asumsi mengenai ketidaknormalan data menurut Ghozali dan Fuad (2005). Peneliti menggunakan asumsi yang kedua yaitu mengestimasi model dengan menggunakan metode maximum likelihood, tetapi mengkoreksi standar error dan beberapa goodness of fit indices akibat ketidaknormalan distribusi data.

\section{Spesifikasi Model}

Pada tahap ini akan dibentuk suatu model yang merupakan pembentukan hubungan antara variabel laten yang satu dengan variabel laten yang lain, maupun variabel laten dengan variabel indikatornya yang didasarkan pada teori yang berlaku.

\section{Identifikasi Model}

Setelah dilakukan spesifikasi model, langkah selanjutnya adalah mengidentifikasi model tersebut.

Dalam analisis SEM diharapkan memperoleh model yang over-identified (df $>0$ ) dan dihindari model yang underidentified $(\mathrm{df}<0)$. pada penelitian ini diperoleh nilai degree of freedom yaitu 32 sehingga model tersebut adalah overidentified.

\section{Estimasi Model}

Setelah dilakukan spesifikasi dan indentifikasi model maka tahap selanjutnya yang dilakukan adalah mengestimasi model. Pada penelitian ini, data tidak berdistribusi normal multivariat sehingga model akan diestimasi menggunakan metote maximum likelihood dengan memperhatikan standar error dan beberapa goodness of fit indices akibat ketidaknormalan data tersebut.

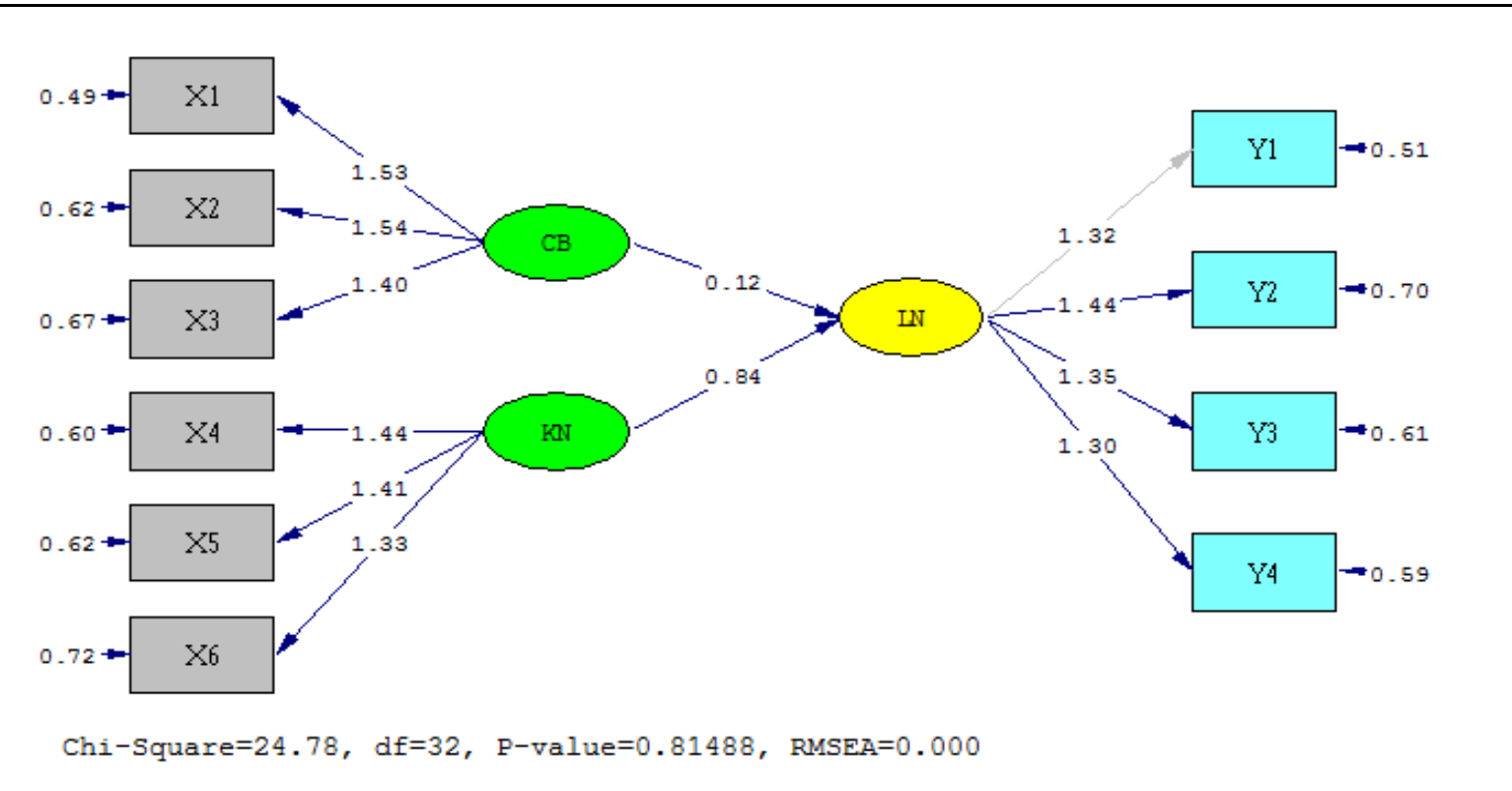

Gambar 1. Diagram Hasil Estimasi Model 


\section{Uji Kecocokan Keseluruhan Model}

Tabel 1. Uji Kecocokan Keseluruhan Model

\begin{tabular}{|c|c|c|c|}
\hline GOF & $\begin{array}{c}\text { Tingkat Kecocokan yang Dapat } \\
\text { Diterima }\end{array}$ & Indeks Model & Keterangan \\
\hline $\begin{array}{l}\text { Chi- } \\
\text { Square }\end{array}$ & $\begin{array}{l}\text { Semakin kecil semakin baik ( } p \text {-value } \\
\geq 0,05 \text { ) }\end{array}$ & $24,78(\mathrm{p}=0,77)$ & Baik \\
\hline NCP & Semakin kecil semakin baik & 0,0 & Baik \\
\hline GFI & $\begin{array}{l}\text { GFI } \geq 0,90 \text { good fit } \\
0,80 \leq \text { GFI } \leq 0,90 \text { marginal fit }\end{array}$ & 0,95 & Good Fit \\
\hline RMSR & RMSR $\leq 0,05$ good fit & 0,049 & Good Fit \\
\hline RMSEA & $\begin{array}{l}\text { RMSEA } \leq 0,05 \text { good fit } \\
\text { Nilai yang kecil dan dekat }\end{array}$ & $\begin{array}{c}0,0 \\
0,96\end{array}$ & $\begin{array}{l}\text { Good Fit } \\
\text { Baik }\end{array}$ \\
\hline ECVI & Dengan ECVI saturated $=1,09$ & & \\
\hline NNFI & $\begin{array}{l}\text { NNFI } \geq 0,90 \text { good fit } \\
0,80 \leq N N F I \leq 0,90 \text { marginal fit }\end{array}$ & 1,00 & Good Fit \\
\hline NFI & $\begin{array}{l}\mathrm{NFI} \geq 0,90 \text { good fit } \\
0,80 \leq N F I \leq 0,90 \text { marginal fit }\end{array}$ & 0,99 & Good Fit \\
\hline AGFI & $\begin{array}{l}\text { AGFI } \geq 0,90 \text { good fit } \\
0,80 \leq A G F I \leq 0,90 \text { marginal fit }\end{array}$ & 0,92 & Good Fit \\
\hline RFI & $\begin{array}{l}\mathrm{RFI} \geq 0,90 \text { good fit } \\
0,80 \leq R F I \leq 0,90 \text { marginal fit }\end{array}$ & 0,98 & Good Fit \\
\hline IFI & $\begin{array}{l}\text { IFI } \geq 0,90 \text { good fit } \\
0,80 \leq I F I \leq 0,90 \text { marginal fit }\end{array}$ & 1,00 & Good Fit \\
\hline CFI & $\mathrm{CFI} \geq 0,90$ good fit & 1,00 & Good Fit \\
\hline PGFI & Nilai lebih tinggi lebih baik & 0,55 & $\begin{array}{l}\text { Kurang } \\
\text { Baik }\end{array}$ \\
\hline $\mathrm{CN}$ & $\mathrm{CFI} \geq 200$ baik & 209,86 & Baik \\
\hline
\end{tabular}

Berdasarkan Hooper et al (2008), meniulai ukuran kecocokan model dengan melihat nilai chi-square, RMSEA, CFI dan RMSR. Oleh karena itu, berdasarkan tabel uji kecocokan keseluruhan model diatas menunjukan model fit maka dapat disimpulkan bahwa model yang digunakan dapat dijadikan dasar analisis terhadap permasalahan penelitian ini.

\section{Uji Kecocokan Model Pengukuran}

Setelah kecocokan model dan data keseluruhan adalah baik, maka langkah selanjutnya adalah menguji kecocokan model pengukuran dengan mengevaluasi setiap variabel laten dengan beberapa indikatornya. Gambar 3 adalah path diagram standardized solution dan Gambar 4 adalah path diagram t-value. 


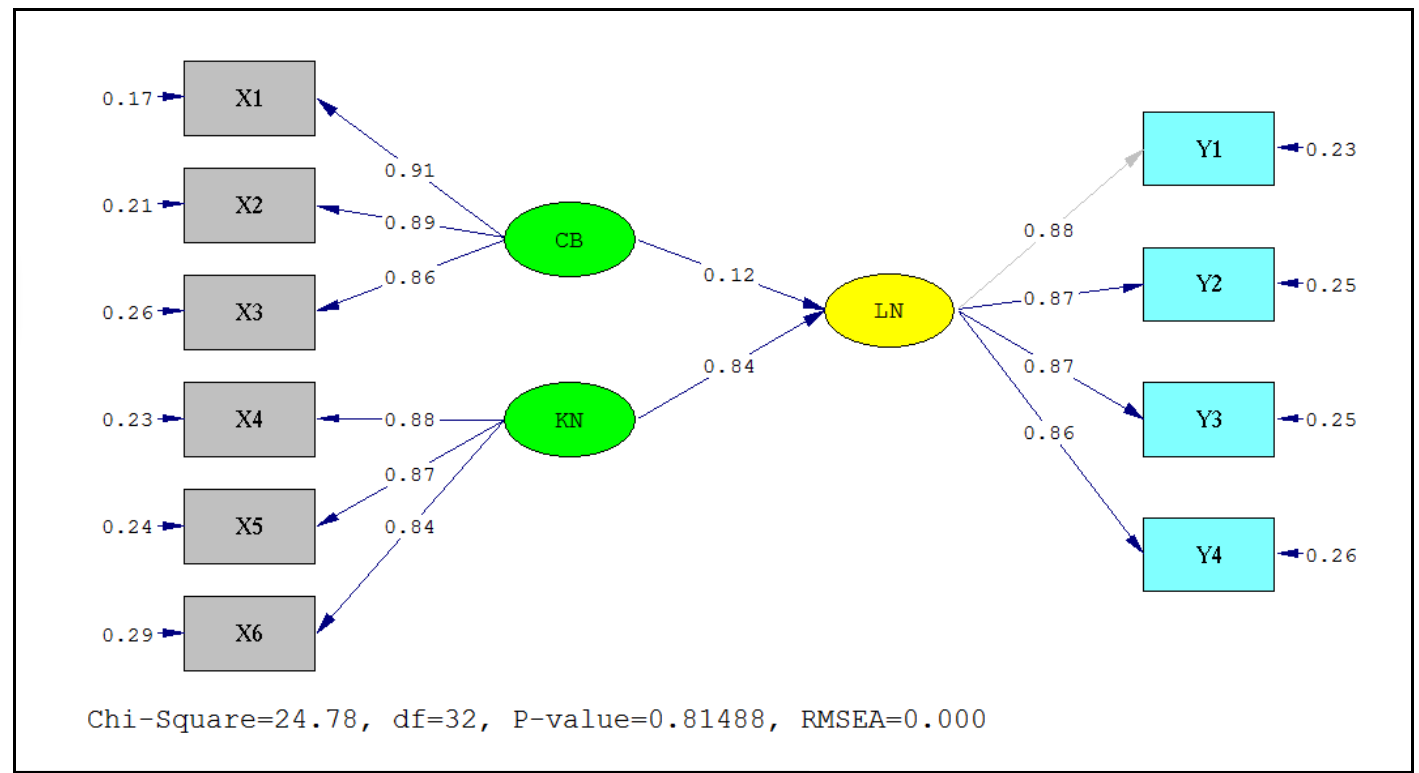

Gambar 2. Path Diagram Standardized Solution

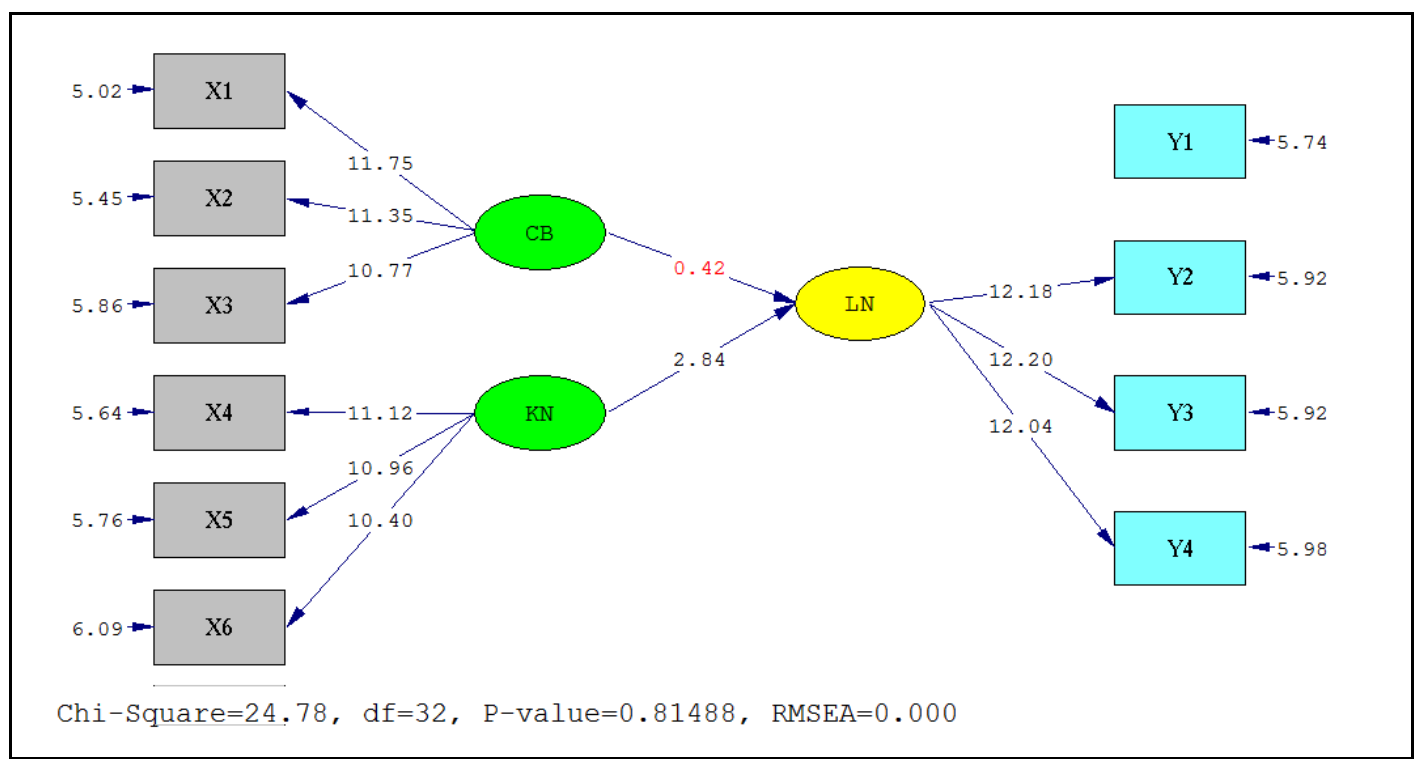

Gambar 3. Path Diagram T-Value 
Pada hasil estimasi t-value terdapat variabel yang tidak memiliki lintasan yaitu variabel LN ke Y1. Hal ini dikarenakan variabel tersebut telah ditetapkan menjadi variance reference yaitu berarti variabel indikator tersebut secara nyata berhubungan dengan variabel latennya.

Pada uji kecocokan model pengukuran akan dilakukan evaluasi terhadap validitas dan evaluasi terhadap reliabilitas model tersebut.

Suatu variabel dikatakan mempunyai validitas yang baik terhadap variabel latennya jika nilai $t$ muatan faktornya (loading factor) lebih besar dari nilai kritisnya (atau $\geq 1,96$ untuk taraf nyata 5\%) dan muatan faktor standarnya (standardized loading factors) $\geq 0,50$. Dan reliabel jika nilai CR (construct reliability) $\geq 0,70$ dan $\mathrm{VE}$ (variance extracted) $\geq 0,50$.

Berdasarkan Tabel 4. didapatkan 10 indikator dengan 3 variabel laten dengan masing-masing indikator telah lolos uji validitas karena memiliki nilai standardized loading factor $\geq 0,50$ dan nilai $t$-value $\geq 1,96$. Dan semua variabel laten $\mathrm{CR} \geq 0,70$ dan $\mathrm{VE} \geq 0,50$ maka dapat dikatakan bahwa jawaban responden terhadap pertanyaanpertanyaan yang diberikan untuk mengukur masing-masing indikator adalah konsisten dan indikator tersebut dapat diandalkan/reliabel.

Tabel 7. Hasil Evaluasi Terhadap Validitas dan Reliabilitas

\begin{tabular}{cccccccc}
\hline $\begin{array}{c}\text { Variabel } \\
\text { Laten }\end{array}$ & $\begin{array}{c}\text { Kode } \\
\text { Indikator }\end{array}$ & $\begin{array}{c}\text { Standardized } \\
\text { Loading } \\
\text { Factors } \\
(\geq 0,50)\end{array}$ & $\begin{array}{c}t \text {-value } \\
(\geq 1,96)\end{array}$ & Ket & $\begin{array}{c}\text { CR } \\
(\geq 0,70)\end{array}$ & $\begin{array}{c}\text { VE } \\
(\geq 0,50)\end{array}$ & Ket \\
\hline Citra & X1 & 0,91 & 11,75 & Valid & & & \\
Bank & X2 & 0,89 & 11,35 & Valid & 0,92 & 0,79 & Reliabel \\
(CB) & X3 & 0,86 & 10,77 & Valid & & & \\
Kepuasan & X4 & 0,88 & 11,12 & Valid & & & Reliabel \\
Nasabah & X5 & 0,87 & 10,96 & Valid & 0,90 & 0,75 & \\
(KN) & X6 & 0,84 & 10,40 & Valid & & & \\
Loyalitas & Y1 & 0,88 & - & & & & \\
Nasabah & Y2 & 0,87 & 12,18 & Valid & 0,92 & 0,75 & Reliabel \\
(LN) & Y3 & 0,87 & 12,20 & Valid & & & \\
\hline
\end{tabular}

Tabel 8. Hasil Analisis Persamaan Struktural

\begin{tabular}{cccc}
\hline $\begin{array}{c}\text { Variabel Laten } \\
\text { Eksogen }\end{array}$ & $\begin{array}{c}\text { Standardized } \\
\text { Cooficient }\end{array}$ & t-value & $\mathrm{R}^{2}$ \\
\hline $\mathrm{CB}$ & 0,12 & 0,42 & 0,92 \\
$\mathrm{KN}$ & 0,84 & 2,84 & 0,94 \\
\hline
\end{tabular}

Evaluasi terhadap model strukutral mencakup pemeriksaan terhadap koefisien-koefisien yang diestimasi. Berdasarka output analisis data, diperoleh hasil persamaan struktural pada Tabel 8 .

Dari hasil penelitian diperoleh persamaan struktural, sebagai berikut:

$$
L N=0,12 C B+0,84 K N .
$$

Berdasarkan Tabel 8 Mengenai persamaan struktural, diperoleh nilai $\mathrm{R}^{2}$ (koefisien determinasi) yang berfungsi untuk menunjukan 
seberapa besar pengaruh antara variabel independen dan dependen. Sehingga dapat disimpulkan bahwa $92 \%$ variasi variabel

Loyalitas Nasabah (LN) dapat dipengaruhi oleh Citra Bank (CB) dan Kepuasan Nasabah (KN).

\section{KESIMPULAN}

Berdasarkan hasil analisis dan pembahasan yang telah diuraikan sebelumnya, maka diperoleh beberapa kesimpulan sebagai berikut :

1. Berdasarkan hasil yang telah didapat pada gambar 4 diperoleh nilai t-value untuk variabel laten citra bank (CB) sebesar $0,42(<1,96)$. Sehingga dapat disimpulkan bahwa variabel citra bank mempunyai pengaruh terhadap loyalitas nasabah.

2. Nilai t-value untuk variabel laten kepuasan nasabah (KN) adalah 2,84 sehingga dapat disimpulkan bahwa variabel laten kepuasan nasabah tidak mempunyai pengaruh terhadap loyalitas nasabah.

\section{DAFTAR PUSTAKA}

Amanullah. A., (2012), Analisis Pengaruh Kualitas Pelayanan Terhadap Kepuasan Nasabah (Studi Kasus pada PD. BKK Wedi Kabupaten Klaten Cabang Karanganom). Universitas Diponegoro. Semarang.

Bielen, Frederic, Nathalie Demoulin, (2007), Waiting Time In Influence on The Satisfaction - Loyal
Relationship in Service. Managing Service Quality, 17(2), 174-193.

Ghozali \& Fuad., (2005), Structural Equation Modeling : Teori, Konsep, dan Aplikasi. Universitas Diponegoro. Semarang

Hooper et.al., (2008), Structural Equation Modeling: Guidelines for Determining Model Fit. The Electronic Journal of Business Research., 6(1), 53-46

Hox, J.J \& Bechger, T. M.,. (1998), An Introduction to Structural Equation Modeling. Family Science Review, 11, 354-373.

Infobank, Januari 2008.

https://www.infobankstore.com/ind ex.php/magezine/detail/2008/195/in fobank-edisi-januari-2008

Liu \& Li Wei Wu. (2007). Customer Retention and Cross-Buying In The Banking Industry : An Integration of Service Attributes, Satisfaction and Trust. Journal of Financial Service Marketing, 12, 132-145.

Prastuti, D,. (2011). Penggunaan Structural Equation Modeling (SEM) Sebagai Salah Satu Teknik Analisis Statistik Dengan Menggunakan Program Tertad IV (Studi Kasus Pengguna Internet dan Hotspot Area di Universitas Negeri Semarang). Universitas Negeri Semarang. Semarang. 